\title{
Early postnatal inhibition of serotonin synthesis results in long- term reductions of perseverative behaviors, but not aggression, in MAO A-deficient mice
}

\author{
Marco Bortolato ${ }^{1}$, Sean C. Godar ${ }^{2}$, Simone Tambaro ${ }^{2}$, Felix G. Li ${ }^{2}$, Paola Devoto ${ }^{5}$, Marcelo \\ P. Coba ${ }^{3}$, Kevin Chen ${ }^{2}$, and Jean C. Shih ${ }^{2,4}$ \\ ${ }^{1}$ Dept. of Pharmacology and Toxicology, School of Pharmacy, University of Kansas, Lawrence, \\ KS, 66045 \\ ${ }^{2}$ Dept. of Pharmacology and Pharmaceutical Sciences, School of Pharmacy \\ ${ }^{3}$ Dept. of Psychiatry and Behavioral Sciences, Keck School of Medicine \\ ${ }^{4}$ Dept. of Cell and Neurobiology, Keck School of Medicine, University of Southern California, Los \\ Angeles, CA, 90033 USA
}

5"Guy Everett" Laboratory, Dept. of Neuroscience "B.B. Brodie”, University of Cagliari, 09124

Monserrato (CA), Italy

\section{Abstract}

\begin{abstract}
Monoamine oxidase (MAO) A, the major enzyme catalyzing the oxidative degradation of serotonin (5-hydroxytryptamine, 5-HT), plays a key role in emotional regulation. In humans and mice, MAO-A deficiency results in high 5-HT levels, antisocial, aggressive, and perseverative behaviors. We previously showed that the elevation in brain 5-HT levels in MAO-A knockout (KO) mice is particularly marked during the first two weeks of postnatal life. Building on this finding, we hypothesized that the reduction of 5-HT levels during these early stages may lead to enduring attenuations of the aggression and other behavioral aberrances observed in MAO-A KO mice. To test this possibility, MAO-A KO mice were treated with daily injections of a 5-HT synthesis blocker, the tryptophan hydroxylase inhibitor p-chloro-phenylalanine (pCPA, $300 \mathrm{mg}$ / $\mathrm{kg} / \mathrm{day}, \mathrm{IP}$ ), from postnatal day 1 through 7 . As expected, this regimen significantly reduced 5-HT forebrain levels in MAO-A KO pups. These neurochemical changes persisted throughout adulthood, and resulted in significant reductions in marble-burying behavior, as well as increases in spontaneous alternations within a T-maze. Conversely, pCPA-treated MAO-A KO mice did not exhibit significant changes in anxiety-like behaviors in a novel open-field and elevated plus-maze; furthermore, this regimen did not modify their social deficits, aggressive behaviors and impairments in tactile sensitivity. Treatment with pCPA from postnatal day 8 through 14 elicited similar, yet milder, behavioral effects on marble-burying behavior. These results suggest that early developmental enhancements in 5-HT levels have long-term effects on the modulation of behavioral flexibility associated with MAO-A deficiency.
\end{abstract}

\footnotetext{
(C) 2013 Elsevier Ltd. All rights reserved.

Corresponding authors: Marco Bortolato, MD PhD, Dept. of Pharmacology and Toxicology, School of Pharmacy, University of Kansas, MH 5040, 1251 Wescoe Hall Dr., Lawrence, KS 66045, Tel.:785-864-1936; Fax: 785-864-5219, bortolato@ ku.edu; Jean C Shih, PhD, Dept of Pharmacology and Pharm Sci, School of Pharmacy, University of Southern California, 1985 Zonal Ave, PSC 518, Los Angeles, CA 90089-9121, Tel.: 323-442-1441; Fax: 323-442-3229, jcshih@usc.edu.

Publisher's Disclaimer: This is a PDF file of an unedited manuscript that has been accepted for publication. As a service to our customers we are providing this early version of the manuscript. The manuscript will undergo copyediting, typesetting, and review of the resulting proof before it is published in its final citable form. Please note that during the production process errors may be discovered which could affect the content, and all legal disclaimers that apply to the journal pertain.
} 


\section{Introduction}

Serotonin (5-hydroxytryptamine, 5-HT) plays a fundamental role in the orchestration of emotional reactivity and in the pathophysiology of numerous mental disorders, ranging from anxiety to pathological aggression (Baldwin and Rudge, 1995; Lucki, 1998; Olivier, 2004). One of the most important mechanisms for the regulation of 5-HT neurotransmission is its metabolism by oxidative deamination, primarily catalyzed by monoamine oxidase (MAO) A (Bortolato et al., 2008; Bortolato et al., 2009). This mitochondrial membrane-bound enzyme, which is encoded by a gene located on the X-chromosome in all vertebrate species (Bortolato et al., 2008), also serves the degradation of other monoamine transmitters, such as norepinephrine (NE) and dopamine (DA) (Shih et al., 1999; Bortolato et al., 2010). The bulk of evidence indicates that low MAO-A brain activity may be a viable marker for the severity of antisocial traits (Alia-Klein et al., 2008). In addition, several studies have documented that $M A O A$ allelic variants associated with low catalytic activity predispose maltreated and abused boys to develop antisocial and aggressive traits (Caspi et al., 2002; Kim-Cohen et al., 2006; Fergusson et al., 2011).

In humans, a nonsense mutation of the MAOA gene results in Brunner syndrome, an Xlinked condition characterized by antisocial and disruptive traits, violent aggression in response to sudden stressors, repetitive behaviors and mild cognitive impairments (Brunner et al., 1993a; Brunner et al., 1993b). Consistently, MAO-A knockout (KO) mice display marked aggression, in association with other phenotypic alterations, including social and communication deficits, perseverative and neophobic-like responses, sensory disturbances, as well as disrupted barrel fields in the somatosensory cortex (Cases et al., 1995; Kim et al., 1997; Godar et al., 2011; Bortolato et al., 2012a). These aberrances are accompanied by elevated 5-HT brain concentrations, particularly during the first two postnatal weeks of life (Cases et al., 1995).

Several findings suggest that the phenotypic abnormalities associated with MAO-A deficiency may depend on their high 5-HT brain levels during early postnatal stages: first, inhibition of 5-HT synthesis with the tryptophan hydroxylase inhibitor $p$-chlorophenylalanine (pCPA) during the first postnatal weeks was shown to normalize barrel field morphogenesis (Cases et al., 1996); second, the aberrant phenotypes in MAO-A KO mice are rescued by the reinstatement of this enzyme in the forebrain at birth (Chen et al., 2007); third, perinatal administration of MAO-A blockers induces long-term aggressive responses and other behavioral changes (Whitaker-Azmitia et al., 1994; Mejia et al., 2002).

In contrast with this background, the long-term impact of early pCPA administration on the aggression and other behavioral impairments of adult MAO-A KO mice has not yet been examined. Thus, in the present study we examined whether pCPA administration in the first two postnatal weeks of life may affect aggression and other behavioral phenotypes of MAOA KO mice, including social deficits, perseverative and alterations of anxiety-like responses. In addition, we verified whether this treatment may induce specific alterations of NMDA glutamate receptor subunit composition, in view of our recent discovery that alterations in this receptor are likely to contribute to the aggression in MAO-A KO mice (Bortolato et al., 2012b).

\section{Materials and methods}

\subsection{Subjects and treatment schedule}

We used experimentally naïve male $129 \mathrm{~S} 6 \mathrm{MAO}-\mathrm{A}^{\mathrm{A} 863 \mathrm{~T}} \mathrm{KO}$ and wild-type (WT) mice, generated and genotyped as previously described (Scott et al, 2008). Since MAO A is 
located on the X-chromosome, mice were bred from WT males crossed with heterozygous MAO-A KO females and litters were culled to 6-8 pups. Animals were injected with either pCPA (300 mg/kg/day, i.p., q.d.; Sigma-Aldrich, St. Louis, MO, USA) or saline solution during the first or the second postnatal week (Fig.1). Intraperitoneal injections were performed at an injection volume of $10 \mathrm{ml} / \mathrm{kg}$, using an injector attached to a micro-syringe. In addition, a group of mice was left untreated to control for the potentially stressful influence of early daily injections. In preliminary studies, we observed that the stress associated with early tattooing or permanent marking led to alterations of maternal behavior (including cannibalism) and/or enduring alterations of stress response. To avoid these potential confounds, all male offspring of each mother (both WT and MAO-A KO littermates) was subjected to the same treatment conditions. Litter effects were minimized by using animals from at least 8 litters for each treatment group for P1-P7 injections and 4 litters for each treatment group for P8-P14 injections. No more than 2 homogenotypic male littermates (randomly selected) in each group were used. Once weaned, male mice were group-housed with other conspecifics from other litters and treatment groups, and received ad libitum access to food and water, in facilities maintained at $22^{\circ} \mathrm{C}$ on a $12 \mathrm{~h}: 12 \mathrm{~h} \mathrm{light/}$ dark cycle.

Mice were isolated on postnatal day 80 (P80) and tested between P90 and P120 (adulthood). This isolation regimen was selected to minimize the potentially detrimental behavioral outcomes of aggressive interactions with MAO-A KO male mice (which display spontaneous aggression towards cage mates); in addition, these conditions are optimal to elicit mild levels of aggressiveness in WT males during the resident-intruder test.

All in vivo experimental procedures were in compliance with the National Institute of Health guidelines and approved by the Animal Use Committees of the University of Southern California and University of Cagliari.

\subsection{Neurochemical analyses}

For biochemical analyses, male mice were deeply anesthetized with isoflurane and promptly decapitated. Brains were removed within approximately $30 \mathrm{~s}$ after decapitation, and forebrain regions were freshly dissected as described by Spijker (2011). Prefrontal cortices were obtained from adult brains by coronal sections (Spijker, 2011). Whole pup forebrains were harvested, to obtain sufficient biological material for further analyses.

2.2.1 HPLC determination of monoamine levels-Forebrain samples were kept in dry ice and rapidly homogenized with an ultrasonic tissue disrupter (Sonoplus HD60, Bandelin, Germany), in a solution containing $0.1 \mathrm{M}$ trichloroacetic acid, $10 \mathrm{mM}$ sodium acetate, and $0.1 \mathrm{mM}$ EDTA; $1 \mu \mathrm{M}$ isoproterenol was used as an internal standard. The homogenates were centrifuged, and the supernatants were used for high performance liquid chromatography (HPLC) analysis. The mobile phase was the same as the homogenization buffer with 7\% methanol for detection of 5-HT. The mobile phase was filtered and deaerated, and the pump speed (Shimadzu LC-6A liquid chromatograph, Columbia, MD, USA) was $1.5 \mathrm{ml} / \mathrm{min}$. The reverse-phase column used was a Rexchrom S50100-ODS C18 column with a length of $25 \mathrm{~cm}$ and an internal diameter of $4.6 \mathrm{~mm}$. The compounds were measured at $+0.7 \mathrm{~V}$ using a Shimadzu L-ECD-6A electrochemical detector.

\subsubsection{Western blot analyses of NMDA receptor subunits-Prefrontal cortex}

samples were homogenized in ice cold buffer (50 mM HEPES, pH 7.4, $40 \mathrm{mM} \beta$-glycerol phosphate, $1 \mathrm{mM}$ sodium orthovanadate, $50 \mathrm{mM}$ Sodium Fluoride, 2mM EDTA, $20 \mu \mathrm{M}$ $\mathrm{ZnCl} 2,1 \%$ Sodium deoxycholate) and protease inhibitors. The homogenates were centrifuged at $75,000 \times g$ for $30 \mathrm{~min}$ at $4^{\circ} \mathrm{C}$ and supernatants used for wester $\mathrm{n}$ blotting 
assays. Equal amounts of protein from each sample $(20 \mu \mathrm{g})$ were used in standard westernblot assays for NR1 (Cell Signaling, Danvers, MA, USA), NR2B and NR2A (NeuroMab, Davis, CA, USA). Blots were developed by chemiluminescence detection in a Kodak 4000MM imaging station. Bands were quantified in arbitrary units and normalized for protein concentrations using $\beta$-actin as loading control.

\subsection{Behavioral testing}

Environmental light and sound levels were maintained at 10 lux and $70 \mathrm{~dB}$ for all behavioral tests unless otherwise indicated. Testing was performed between 10 am and $3 \mathrm{pm}$ with lights on at 6 am in the listed sequence below. Experiments on animals injected during the first and second postnatal weeks were performed and analyzed separately. All behaviors were videorecorded and analyzed by trained observers, who were blind to the genotype and treatment of the mice. To reduce carryover effects due to stress ensuing repeated testing, each animal was used for no more than 3 different tests (with a time interval of at least 1 week between two consecutive tests) and the order of testing was randomized (with the exception of social interaction and resident-intruder aggression tests, which were always performed at the end of behavioral batteries).

2.3.1. Open field-Analysis of open-field behaviors was performed to assess locomotor and exploratory responses, as well as anxiety-related reactivity. Testing was performed in a Plexiglas square grey arena $(40 \times 40 \mathrm{~cm})$ surrounded by 4 black walls $(40 \mathrm{~cm} \mathrm{high),} \mathrm{based}$ on a modified version of the protocol detailed elsewhere (Bortolato et al, 2011). On the floor, two zones of equivalent areas were defined: a central square quadrant and a concentric peripheral frame. Mice $(\mathrm{n}=11-13$ mice per group) were placed in the central zone and their behavior was monitored for 5 min using Ethovision behavioral tracking software (Noldus Instruments, Wageningen, The Netherlands). Behavioral measures included the total locomotor activity, time spent in the center, and the percent locomotor activity in the center (calculated as the distance traveled in the center over the total distance traveled).

2.3.2. Elevated plus-maze-The elevated plus-maze protocol was used to measure contextual anxiety and performed as previously described (Pellow et al, 1985; Bortolato et $a l, 2009)$. Briefly, the apparatus was comprised of two open arms and two closed arms in black Plexiglas with a light grey floor, which extended from a central platform. Mice ( $\mathrm{n}=$ 11-13 per group) were placed individually on the central platform, facing an open arm, and allowed to explore the maze for $5 \mathrm{~min}$. An arm entry was counted only when all four paws were inside the arm. Behavioral measures included the number of entries and time spent in each compartment of the maze, as well as the number of stretch-attend postures and head dips (previously defined in Godar et al, 2011).

2.3.3. Novel object exploration-Novel object exploration was tested to assess exploratory responses and neophobia. The assay was conducted in the home cage to maximize neophobic responses in MAO-A KO mice as previously detailed (Godar et al, 2011). Two novel black plastic cylinders ( 8 - $\mathrm{cm}$ high; $3.5 \mathrm{~cm}$ diameter) were symmetrically placed in the cage. Mice ( $\mathrm{n}=8-10$ per group) were allowed to freely explore the objects and environment for $15 \mathrm{~min}$. Exploration was defined as sniffing or touching the object with the snout, and measured as the frequency and total time spent exploring both objects; climbing on the object was not considered exploration.

2.3.4. Marble burying - This paradigm was used to capture anxiety-driven perseveration. Testing was performed in Makrolon cages containing $5 \mathrm{~cm}$ of sawdust, as previously described (Bortolato et al, 2009). Mice ( $\mathrm{n}=11-13$ per group) were individually placed in the cage and their behavior was monitored for $30 \mathrm{~min}$. Mice were removed and 20 glass marbles 
( $1.5 \mathrm{~cm}$ in diameter) were placed on the sawdust at equal distances. The animal was then reintroduced into the cage and its behavior was monitored for 30 additional min. The number of buried marbles was counted; a marble was considered buried if at least two-thirds of its surface area was covered in sawdust.

2.3.5. Spontaneous alternations in the T-maze-To ascertain the potential effect of pCPA on perseverative responses, spontaneous alternations were tested in a T-maze, as previously described (Bortolato et al, 2012). Briefly, each session consisted of eight consecutive trials. In each trial, the mouse ( $\mathrm{n}=10-12$ per group) was placed in the start compartment of a T-maze. After $15 \mathrm{~s}$, the door was lifted and the mouse was left free to explore the two arms of the maze. As soon as the animal entered (with all four paws) one of the two alternative arms (left or right), the door of that compartment was closed for $15 \mathrm{~s}$ to confine the animal. The animal was removed between trials and the T-maze was quickly cleaned and dried to remove any olfactory cue that may condition the performance in the next trial. A trial was considered failed if the animal did not enter an arm within $120 \mathrm{~s}$. Mice that recorded two failures were eliminated from testing. The percentage of arm alternations was analyzed for each mouse.

2.3.6. Social interaction-Mice were tested as described elsewhere (Bortolato et al, 2011). Mice ( $n=9-10$ per group) were placed into a neutral, unfamiliar Makrolon cage, with foreign age- and weight-matched male WT conspecifics (from separate litters). Testing sessions lasted $10 \mathrm{~min}$ and were scored for social behaviors, which consisted of the number and overall duration of social exploratory approaches towards the conspecifc (defined as investigative sniffing of the facial and anogenital areas of the conspecific).

2.3.7. Resident-intruder aggression-Testing was conducted as previously described (Bortolato et al, 2011). To study aggression, animals were isolated at P80 for 14 days, a duration that we have previously identified as optimal to establish aggression in MAO-A $\mathrm{KO}$ males. Following a 30-min habituation period within the home cage in the experimental room, mice ( $\mathrm{n}=12-14$ per group) were exposed to age- and weight-matched WT males (previously acclimated to the same room) from different litters, for $10 \mathrm{~min}$. Measures included the number and duration of fighting bouts.

2.3.8. Sticky-tape test-The sticky-tape test was carried out as described elsewhere (Bortolato et al, 2012), to measure potential deficits in sensorimotor reflexes in MAO-A KO mice. Animals $(n=9-11$ per group) were briefly restrained and a circular piece of tape (5 $\mathrm{mm}$ in diameter) was placed on the bottom of each forepaw. The time to remove each piece of tape was recorded.

2.3.9. Hot plate-To assess the impact of pCPA on pain sensitivity, mice were tested on a hot plate (IITC, Woodland Hills, CA, USA) as previously described (Bortolato et al, 2012). Mice ( $\mathrm{n}=11-13$ per group) were placed on the hot plate and the latency to lick their paws was measured; a 20-s cut-off time was used to avoid potential tissue damage. The hot plate was maintained at $52.5^{\circ} \mathrm{C}$, as this temperature was shown to elicit a significant delay in pawlicking latency in MAO-A KO mice (Bortolato et al, 2012).

\subsection{Statistical analyses}

Normality and homoscedasticity of data distribution were verified by using KolmogorovSmirnov and Bartlett's tests. Statistical analyses on parametric data were performed using two-way ANOVAs, followed by Newman-Keuls test for post-hoc comparisons. Significance threshold was set at 0.05 . All statistical analyses were performed by STATISTICA 7 (Statsoft, Tulsa, OK). 


\section{Results}

\subsection{Neurochemical analyses}

\subsubsection{Forebrain 5-HT levels in 8-day old mice-We ascertained that $\mathrm{pCPA}$} administration resulted in the normalization of forebrain 5-HT levels in MAO-A KO pups at postnatal day 8 . We found that this treatment in the first week led to a reduction in 5-HT concentrations across both genotypes (Table 1). Significant main effects of genotype $[F(1$, $30)=114.58 ; \mathrm{P}<0.001$, ANOVA $]$ and treatment $[\mathrm{F}(2,30)=49.10 ; \mathrm{P}<0.001$, ANOVA $]$ were detected. In addition, a significant genotype $\times$ treatment interaction was found $[\mathrm{F}(2,30)=$ 17.18; $\mathrm{P}<0.001$, ANOVA]. Post-hoc analyses revealed that untreated and saline-injected MAO-A KO pups had higher 5-HT forebrain concentrations than their WT counterparts ( $\mathrm{P}<0.001$ for both comparisons). In WT mice, $\mathrm{pCPA}$ administration significantly reduced 5HT levels in comparison with both untreated $(\mathrm{P}<0.05)$ and saline-injected $(\mathrm{P}<0.05)$ counterparts. Similarly, pCPA treatment produced a marked decrement in forebrain 5-HT concentrations in MAO-A KO mice, as compared with both untreated and saline-treated (Ps $<0.001$ for both comparisons) animals.

3.1.2. Prefrontal $5-\mathrm{HT}$ levels in adult mice-Early pCPA treatment resulted in longterm reductions in 5-HT levels also in the prefrontal cortex of adult (90-day old) WT and MAO A-KO mice (Table 1). Indeed, ANOVA identified significant main effects of genotype $[\mathrm{F}(1,42)=20.81 ; \mathrm{P}<0.001]$ and treatment $[\mathrm{F}(2,42)=53.30 ; \mathrm{P}<0.001]$, as well as a significant genotype $\times$ treatment interaction $[\mathrm{F}(2,42)=7.42 ; \mathrm{P}<0.01]$. Post-hoc comparisons revealed that this latter effect was due to significant differences between untreated WT and MAO A KO mice $(\mathrm{P}<0.01)$, saline-treated WT and MAO A KO mice $(\mathrm{P}<0.001)$, as well as pCPA-treated mice and their untreated or saline-injected counterparts ( $\mathrm{Ps}<0.01$ for all comparisons; Newman-Keuls).

\subsubsection{Prefrontal NMDA receptor (NMDAR) subunit expression in adult mice-} To verify whether pCPA treatment may affect NMDAR subunit composition, we measured NR1, NR2A and NR2B levels in the prefrontal cortex of pCPA-treated WT and MAO-A KO mice, as compared with their saline-injected counterparts. As shown in Table 2, we found that NR1 [Main effect of genotype: $F(1,15)=0.51, \mathrm{NS}]$ and NR2A $[\mathrm{F}(1,15)=0.51, \mathrm{NS}$ ] subunits were not altered in MAO-A KO mice; conversely, NR2B subunits were significantly increased $[\mathrm{F}(1,15)=22.84, \mathrm{P}<0.001]$ in MAO-A KO mice, as compared to WT counterparts. Notably, early postnatal pCPA administration did not affect the expression of any of these subunits [genotype $\times$ treatment interactions: NR1: $F(1,15)=0.51$, NS; NR2A: $\mathrm{F}(1,15)=0.06, \mathrm{NS} ; \mathrm{NR} 2 \mathrm{~B}: \mathrm{F}(1,15)=0.07, \mathrm{NS}]$.

\subsection{Behavioral testing}

3.2.1. Open field-The analysis of overall locomotor activity in a novel open field (Fig. $2 \mathrm{~A}$ ) revealed a significant main effect of genotype $[\mathrm{F}(1,53)=12.82 ; \mathrm{P}<0.001]$, but not treatment; furthermore, no significant genotype $\times$ treatment interactions were found, signifying that the hypolocomotion of MAO-A KO mice was not affected by early pCPA or saline administration. The analysis of the time spent in the center quadrant of the open field (Fig.2B) revealed significant main effects of both genotype $[\mathrm{F}(1,54)=4.14 ; \mathrm{P}<0.05]$ and treatment $[\mathrm{F}(2,54)=5.53 ; \mathrm{P}<0.01]$, but no interactions between the two factors. Similarly, the analysis of percent locomotor activity in the center (Fig. 2C) disclosed a statistical trend for a main effect of genotype $[\mathrm{F}(1,54)=3.91 ; \mathrm{P}<0.06]$ and a significant effect for treatment $[\mathrm{F}(2,54)=3.82 ; \mathrm{P}<0.05]$, but no genotype $\times$ treatment interactions.

3.2.2. Elevated plus-maze-In parallel with our findings in the open field, MAO-A KO mice exhibited a reduced number of total entries (Fig.3A) [Main effect of genotype: F(1, 64) 
$=6.10 ; \mathrm{P}<0.05]$ in the elevated plus-maze. Although the analysis of the percent entries in the open (Fig.3B) and closed (Fig.3E) arms revealed significant genotype $\times$ treatment interactions [\%open entries: $\mathrm{F}(2,64)=3.74 ; \mathrm{P}<0.05 ; \%$ closed entries: $\mathrm{F}(2,64)=3.18$; $\mathrm{P}<0.05]$, post-hoc comparisons did not identify any significant changes between any genotype $\times$ treatment groups, but only a statistical trend $(\mathrm{P}<0.10)$ for an increase in open entries by MAO-A KO mice. Early pCPA administration was found to significantly increase the time spent by MAO-A KO mice in the open arms (Fig.3C) [genotype $\times$ treatment interaction: $F(2,64)=5.04 ; \mathrm{P}<0.01]$. This effect was found to depend on a significant difference $(\mathrm{P}<0.05)$ between $\mathrm{pCPA}$ - and saline-treated MAO-A KO mice. Conversely, no significant difference was found between treatment groups of WT mice; furthermore, no differences were found between WT and MAO-A KO mice with respect to any treatment condition. Treatment with pCPA did not significantly affect the time spent in the central platform (Fig.3D) $[\mathrm{F}(2,64)=0.12 ; \mathrm{NS}]$ or in the closed arms (Fig.3F) $[\mathrm{F}(2,64)=2.06$; NS] As previously described (Godar et al, 2011), MAO-A KO mice also exhibited reductions in stretch-attend postures (Fig. 3G) $[\mathrm{F}(1,64)=8.78$; $\mathrm{P}<0.01$; Main effect of genotype $]$ and head dips (Fig. $3 \mathrm{H})[\mathrm{F}(1,64)=8.41 ; \mathrm{P}<0.01$; Main effect of genotype $]$ compared to WT mice. Nevertheless, these effects were not significantly affected by pCPA treatment, as revealed by the lack of significant treatment $\times$ genotype interaction for either parameter [stretchattend postures: $\mathrm{F}(2,64)=0.15$; NS; head dips: $\mathrm{F}(2,64)=0.46$; NS]. Similar to the open field, MAO-A KO animals showed a significant reduction in the overall distance travelled in the elevated plus maze [genotype: $\mathrm{F}(1,64)=6.10 ; \mathrm{P}<0.05$ ] (untreated WT: $1012.39 \pm 81.35$ $\mathrm{cm}$; untreated MAO-A KO: $911.69 \pm 66.48 \mathrm{~cm}$; saline-treated WT: $1044.28 \pm 59.88 \mathrm{~cm}$; saline-treated MAO-A KO: $887.88 \pm 39.26 \mathrm{~cm}$; pCPA-treated WT $1057.1 \pm 40.25 \mathrm{~cm}$; pCPA-treated MAO-A KO: $948.73 \pm 34.98 \mathrm{~cm}$ ).

\subsubsection{Novel object exploration-In comparison with WT mice, MAO-A KO} littermates engaged in fewer exploratory approaches towards novel objects (Fig.4A) [genotype $\times$ treatment interaction: $\mathrm{F}(2,49)=10.45 ; \mathrm{P}<0.001$ ]. Post-hoc comparisons identified a significant difference $(\mathrm{P}<0.001)$ between untreated WT and MAO-A KO mice; notably, this deficit was rescued by early pCPA treatment ( $\mathrm{Ps}<0.05$ for comparisons between pCPA-treated MAO-A KO and either non-treated or saline-injected MAO-A KO mice). Furthermore, both saline and pCPA treatment reduced the number of exploratory approaches in WT mice $(\mathrm{P}<0.05$ and $\mathrm{P}<0.01$ for comparisons between saline-treated WT and pCPA-treated WT vs untreated WT, respectively). All other comparisons between genotype $\times$ treatment combinations did not reveal any significant difference. The analysis of the sniffing duration (Fig.4B) confirmed that, while MAO-A KO mice explored the novel objects for a significantly shorter time [genotype $\times$ treatment: $\mathrm{F}(2,49)=6.16$; $\mathrm{P}<0.01$; $\mathrm{P}<0.01$ for comparison between non-treated WT and MAO-A KO mice], this impairment was fully prevented by pCPA administration $(\mathrm{P}<0.001)$. The analysis of the latencies to the first exploratory approach (Fig. 4C) revealed significant main effects of the genotype $[\mathrm{F}(1,49)=12.78 ; \mathrm{P}<0.001]$ and treatment $[\mathrm{F}(2,49)=5.27 ; \mathrm{P}<0.01]$, as well as a significant genotype $\times$ treatment interaction $[\mathrm{F}(2,49)=5.06, \mathrm{P}<0.05]$. Post-hoc comparisons revealed that untreated MAO-A mutants had a significantly longer latency to explore novel objects than WT counterparts $(\mathrm{P}<0.001)$. This latency was reduced by pCPA $(\mathrm{P}<0.001)$ and, to a lesser extent, by saline treatment $(\mathrm{P}<0.05)$. Neither pCPA nor saline affected the same parameters in WT mice. No significant difference among groups was found in locomotor activity (data not shown).

3.2.4. Marble burying-As previously shown (Bortolato et al., 2012a), MAO-A KO mice buried a greater number of marbles (Fig. 5A) [genotype $\times$ treatment: $F(2,57)=8.75$; $\mathrm{P}<0.001]$ than WT littermates. This alteration was prevented by pCPA pre-treatment $(\mathrm{P}<0.001$ and $\mathrm{P}<0.01$ for comparisons between $\mathrm{pCPA}$-treated MAO-A KO vs non-treated 
and saline-injected MAO-A KO mice, respectively). In addition, the analysis of digging duration showed a main effect of the genotype $[\mathrm{F}(1,56)=8.66 ; \mathrm{P}<0.01]$, but no significant genotype $\times$ treatment interaction (data not shown).

3.2.5. Spontaneous alternations in the T-maze-In line with our previous findings (Bortolato et al., 2012a), we confirmed that MAO-A KO mice engaged in a significantly lower percentage of spontaneous alternations (Fig. 5B) [genotype $\times$ treatment: $F(2,55)=$ 6.47; $\mathrm{P}<0.01 ; \mathrm{P}<0.05$ for comparison between non-treated WT and MAO-A KO mice]. This effect, however, was rescued by early postnatal pCPA treatment $(\mathrm{P}<0.05$ for comparisons between pCPA-treated MAO-A KO and either non-treated or saline-injected MAO-A KO).

3.2.6. Social interaction and resident intruder task-MAO-A KO mice displayed a significant reduction in the frequency (Fig.6A) [genotype: $\mathrm{F}(1,39)=29.46 ; \mathrm{P}<0.001$ ] and duration (Fig.6B) [genotype: $\mathrm{F}(1,40)=27.34 ; \mathrm{P}<0.001$ ] of social exploration. In addition, we found a significant treatment effect for the number of social approaches $[F(2,39)=4.00$; $\mathrm{P}<0.05]$. No significant interactions between genotype $\times$ treatment were found. The locomotor activity was comparable across experimental groups (data not shown).

In the resident-intruder paradigm, MAO-A KO mice exhibited an increased number of fighting bouts (Fig.6C) [Main effect of genotype: $\mathrm{F}(1,50)=49.50 ; \mathrm{P}<0.001$ ] and fighting duration (Fig.6D) [Main effect of genotype: $\mathrm{F}(1,50)=30.57$ : $\mathrm{P}<0.001$ ]. Moreover, a significant treatment effect was detected for both parameters [bouts: treatment: $\mathrm{F}(2,50)=$ 4.62; $\mathrm{P}<0.05$ and duration: treatment: $\mathrm{F}(2,50)=4.00 ; \mathrm{P}<0.05$ ]. No significant differences in genotype $\times$ treatment interactions were detected. All groups displayed equivalent locomotor activities (data not shown).

3.2.7. Sticky-tape and hot plate tests-As previously shown (Bortolato et al., 2012a), MAO-A KO mice exhibited a significant increase in the latency to remove sticky tape from their forepaws (Fig.7A) [Main effect of genotype: $\mathrm{F}(1,48)=19.80$; $\mathrm{P}<0.001$ ]. In parallel, MAO-A-deficient mice displayed an enhanced latency to lick their paws in response to the exposure to a hot plate (Fig.7B) [Main effect of genotype: $\mathrm{F}(1,60)=6.02 ; \mathrm{P}<0.05$ ] Notably, neither alteration was affected by pCPA treatment.

3.2.8. Effects of PCPA administration between P8 and P14-MAO-A mutants treated with pCPA during the second postnatal week exhibited a significant reduction in marble burying activity (Fig. 8A) [genotype $\times$ treatment: F(2, 32) $=4.10 ; \mathrm{P}<0.05$ ]. Post-hoc analyses revealed that, while non-treated MAO-A KO mice buried significantly more marbles than their non-treated WT counterparts, both saline $(\mathrm{P}<0.05)$ and pCPA $(\mathrm{P}<0.01)$ markedly reduced this behavior. MAO-A-deficient animals showed a significant reduction in exploratory approaches towards an unfamiliar object [main effect for genotype: $\mathrm{F}(1,31)=13.77 ; \mathrm{P}<0.001]$. In addition, ANOVA detected a main effect of treatment $[\mathrm{F}(2,31)=40.46 ; \mathrm{P}<0.001]$ and a significant genotype $\times$ treatment interaction $[\mathrm{F}(2,31)=$ 6.07; P<0.01] (Fig. 8B). Newman-Keuls test disclosed that untreated MAO-A KO mice exhibited a significantly lower number of approaches in comparison with their WT counterparts $(\mathrm{P}<0.001)$. In addition, saline and pCPA treatment significantly reduced the same parameters in both WT (Ps $<0.001$ for both comparisons) and MAO-A KO mice $(\mathrm{Ps}<0.05)$. The analysis of the duration of novel-object exploration disclosed a main genotype effect $[\mathrm{F}(1,31)=6.73 ; \mathrm{P}<0.05]$, but no significant genotype $\times$ treatment interactions $[\mathrm{F}(1,31)=0.78 ; \mathrm{NS}]($ Fig. 8C).

The analysis of resident-intruder aggression revealed that MAO-A KO mice displayed a significantly higher number of fighting episodes [Main effect of genotype: $F(1,61)=7.92$; $\mathrm{p}<0.01$ ], but this difference was not affected by treatment [genotype $\times$ treatment: $F(2,61)=$ 
0.82; NS] (Fig. 8D). Overall fighting duration was also significantly greater in MAO-A deficient animals [Main effect of genotype: $F(1,60)=8.85 ; \mathrm{p}<0.01$ ]. In addition, a significant genotype $\times$ treatment interaction was found $[\mathrm{F}(2,60)=3.36$; $\mathrm{P}<0.05]$. Post-hoc analyses showed that, while non-treated MAO-A KO mice engaged in significantly longer fighting behaviors than their untreated WT counterparts $(\mathrm{P}<0.01)$, pCPA pretreatment increased this parameter in WT $(\mathrm{P}<0.05)$, but not in MAO-A KO mice.

\section{Discussion}

The results of the present study showed that neonatal subchronic administration of pCPA, the prototypical inhibitor of tryptophan hydroxylase, produced an enduring reduction of brain 5-HT forebrain levels in WT and MAO-A KO mice, which lasted until adulthood. These neurochemical changes led to a complex alteration of the abnormal phenotypes associated with MAO A deficiency. On one hand, counterbalancing the early elevation of 5HT in MAO-A KO pups preserved the microcolumnar pattern in the barrel fields of the somatosensory cortex (Cases et al., 1996), and led to a marked attenuation of their perseverative and restricted responses, such as marble burying and lack of spontaneous alternations in a T-maze (Bortolato et al., 2011; Bortolato et al., 2012a). On the other hand, pCPA treatment from postnatal day 1 through 7 did not rescue the overtly aggressive responses, social deficits and tactile alterations associated with MAO-A deficiency (Cases $e t$ al., 1995; Scott et al., 2008; Bortolato and Shih, 2011; Bortolato et al., 2012a). In addition, this treatment had only limited effects on behavioral responses related to multiple facets of anxiety-like behavior. Indeed, in the open field, it did not result in significant changes in thigmotactic behavior. Furthermore, in the elevated plus maze pCPA reduced the total duration spent by MAO-A KO mice in the open arms, but produced only a statistical trend for a reduction (rather than a significant effect) of the number of open-arm entries and failed to ameliorate their reduction in stretch-attend postures and head dips. Finally, pCPA increased the number of exploratory approaches performed by MAO-A KO mice towards unfamiliar objects (Godar et al, 2011); however, this amelioration was not accompanied by a selective effect of this drug (as compared to saline treatment) on either the overall exploratory duration or the latency to the first approach to the novel object.

Our findings also documented that pCPA treatment during the second week of postnatal life elicited a similar, albeit milder, attenuation of repetitive behaviors in MAO-A KO mice. Collectively, these data strongly suggest that, in mice, the first (and, to a lesser extent, the second) week of postnatal life is a critical stage for the role of MAO-A and 5-HT in brain and behavioral development. These results also complement previous evidence reported by our group and others, indicating that the abnormal phenotypes of MAO-A KO mice are influenced by early developmental neurochemical imbalances. In fact, the perturbations featured by these mutants were rescued by the genetic reinstatement of forebrain MAO-A from postnatal day 1 onwards (Chen et al., 2007); in addition, pharmacological inhibition of MAO-A in perinatal periods was shown to elicit long-term behavioral sequelae in rodents (Boylan et al., 2000; Mejia et al., 2002).

We recently documented that MAO-A KO mice, in addition to their aggressive responses, display a spectrum of behavioral alterations reminiscent of the key pathognomonic deficits of autism-spectrum disorder (ASD), including social deficits, reduced communication and repetitive, restricted behaviors (Bortolato et al., 2012a). An increased risk of social, communicative, cognitive and neuromorphological impairments in ASD were also found in subjects carrying polymorphic variants associated with low MAO-A catalytic activity (Yirmiya et al., 2002; Cohen et al., 2003; Davis et al., 2008; Cohen et al., 2011). Our data show that the perseverative and restricted behaviors in MAO-A KO mice may indeed be supported by the high levels of 5-HT in early postnatal stages. This finding is consistent 
with the well-documented link between ASD and hyperserotonemia (Schain and Freedman, 1961; Ritvo et al., 1970; Anderson et al., 1987; Anderson et al., 1990; Mulder et al., 2004). In particular, it is worth noting that recent studies have raised the possibility that high 5-HT concentrations may result in stereotyped behavior and delays in age of social smile in ASD patients (Sacco et al., 2010; for contrasting results see Kolevzon et al., 2010).

Previous reports documented that perinatal and neonatal pCPA treatment rescued early neurological deficits and the dysmorphogenesis of the barrel cortex in MAO-A KO mice (Cases et al., 1995; Cases et al., 1996). It has been clarified that the critical period for MAOA inhibition to result in impairments of the barrel cortex is limited to the first week of postnatal life (Vitalis et al., 1998; Boylan et al., 2000). While our data cannot substantiate a causal nexus between the restorative action of pCPA on corticogenesis and perseverative behaviors, it is worth noting that the barrel fields afford a well-characterized template of minicolumnar organization (Bruno et al., 2003), whose abnormalities have been posited to underlie ASD pathophysiology (Casanova et al., 2002; Casanova et al., 2006). These premises support the possibility that 5-HT input in perinatal periods may govern the ontogenesis of brain circuits subserving behavioral plasticity; alterations of these processes may lead to impaired cortical development and specific aberrances of information processing.

Early pCPA treatment induced a permanent reduction of 5-HT levels in the prefrontal cortices of WT and MAO-A KO mice. The bases of this phenomenon, albeit still unknown, are likely reflect the modulatory influence of 5-HT on early neurogenesis, developmental cellular migration and cytoarchitecture (Lauder and Krebs, 1978; Daubert and Condron, 2010). In particular, recent evidence indicates that 5-HT autoregulates the morphology and innervation of its own system (Daubert and Condron, 2010); furthermore, the inhibition of 5-HT synthesis by pCPA at different developmental stages has been shown to affect cortical connectivity and development (Chen et al., 1994; Vitalis et al., 2007). Thus, it is possible that early treatment with the tryptophan hydroxylase inhibitor may cause persistent reductions and/or damages in 5-HTergic fibers in the prefrontal cortex.

Irrespective of the mechanisms accounting for the enduring reduction in prefrontal 5-HT content in pCPA-treated mice, this alteration may account for some of our behavioral findings, such as the lack of ameliorative effects of this regimen on the social deficits and aggression displayed by adult MAO-A KO mice. In fact, most studies have reported a consistent link between 5-HT hypofunction and impulsive aggression in vertebrates (Coccaro, 1989; Virkkunen and Linnoila 1993; Miczek et al., 2001). Deficits in prefrontal 5HT content are posited to be particular relevant for the control of aggression, insofar as they may lead to an insufficient inhibition of affective triggers of impulsive aggression in limbic areas (Amen et al., 1996). Accordingly, our tests showed that early pCPA treatment selectively increased fighting duration in WT mice. Thus, it is possible that the persistent reduction of 5-HT in the prefrontal cortex may intrinsically lead to an intrinsic enhancement of aggression in adulthood, which could mask and override potential beneficial effects on the early developmental bases of impulsive hostility in MAO-A KO mice. Similar views may help explain the failure of early pCPA treatment to enhance social interaction and modify most anxiety-related responses in these mutants.

Alternatively, our behavioral results may subtend a phenomenological dissociation between aggression vulnerability and early elevation of 5-HT levels, which may challenge the possibility of a primary role for this neurotransmitter in the high aggressiveness of MAO-A $\mathrm{KO}$ mice. For example, it is possible that the high proclivity of MAO-A KO mice to engage in antagonistic behaviors may depend on high levels of other MAO-A substrates, such as DA and NE. Indeed, mice with null-allele mutations of DA transporter, NE transporter and 
catechol-O-methyl-transferase (COMT), which feature high levels of catecholamines, have been shown to be significantly more aggressive than WT conspecifics (Gogos et al., 1998; Haller et al., 2002; Rodriguiz et al., 2004; Volavka et al., 2004; Guo et al., 2007; Bedard et al., 2010). Given that the elevation in catecholamine levels in MAO-A KO mice occurs mainly after the second postnatal week of life (Cases et al., 1995), the potential contribution of DA and NE to aggression may occur upon periadolescent stages, underscoring the possibility of multiple critical developmental stages with respect to different neurochemical substrates and behavioral outcomes.

We recently reported that MAO-A KO mice display changes in NMDAR subunit composition in the prefrontal cortex. These alterations appear to play a critical role in the aggressive responses enacted by MAO-A KO mice, as these behaviors are suppressed by NMDAR antagonists (Bortolato et al, 2012b). Notably, the present results show that early pCPA treatment did not alter the subunit expression of prefrontal NMDA receptors in MAOA KO mice, further supporting a critical role of these ionotropic channels in the pathogenesis of aggression in these animals. We confirmed that the expression of NR2B, but not NR1, was increased in the composition of NMDA receptors in the prefrontal cortex of MAO-A KO mice. In contrast, no significant enhancement of NR2A was found, possibly signifying a lesser involvement of this subunit in the behavioral aberrances in MAO-A KO mice. Recent findings have documented that NR2B subunits in the prefrontal cortex are required to regulate synaptic plasticity and working memory (Cui et al., 2011; Wang et al., 2013), by interacting with calcium/calmodulin-dependent protein kinase II (CaMKII) (Strack et al., 2000; Fink and Meyer, 2002).

Our behavioral assessments revealed that early saline treatment produced a number of specific changes in both WT and MAO-A KO mice in comparison with their non-treated counterparts. For example, we found that this treatment reduced the number of exploratory approaches directed towards novel objects in WT mice. These data suggest that the stress caused by daily punctures during the first postnatal week may result in enduring enhancements in neophobia or reduction in novelty-seeking behavior, and are in alignment with ample evidence indicating a link between early childhood traumas and the development of anxiety-related symptoms in adult life (Heim and Nemeroff, 2001).

From a translational perspective, our findings temper the possibility that the early inhibition of 5-HT synthesis may be a viable approach to prevent the aggressive and antisocial traits associated with low brain MAO-A activity (Alia-Klein et al., 2008). Nevertheless, our results cannot rule out that these behavioral problems may be efficiently countered by more specific approaches aimed at the reduction of the early impact of 5-HT within select brain regions and/or receptor subtypes. Ample evidence has shown that aggression is associated with different changes in 5-HTergic activity across multiple areas within the aggression circuitry (Summers et al., 2005). Moreover, different 5-HT receptor families mediate opposite modulatory effects on distinctive aspects of aggression (Takahashi et al., 2011; Bortolato et al., 2013); for example, while the genetic and pharmacological inactivation of $5-\mathrm{HT}_{1 \mathrm{~B}}$ receptors increases the levels of aggression (Saudou et al., 1994), 5-HT $2 \mathrm{~A}$ receptor antagonists exert anti-aggressive properties (Shih et al., 1999). Thus, the global reduction of 5-HT synthesis induced by pCPA may have actually reversed some imbalances related to aggression in MAO-A KO mice, but these effects may be masked by alterations related to impaired signaling of other 5-HT receptors or in specific subcortical regions. Notably, the dysmorphogenic effect of excessive 5-HT on the barrel fields in MAO-A KO mice has been shown to depend the overactivation of 5-HT $1 \mathrm{~B}$ receptors (Vitalis et al.,1998; Salichon et al., 2001). Further studies will be necessary to evaluate the specific contribution of different 5$\mathrm{HT}$ receptor subtypes and brain regions to the aggressive phenotype of MAO-A KO mice. 


\section{Conclusions}

The results of the present study indicate that alterations in perseverative behaviors associated with MAO-A deficiency are supported by high 5-HT levels in early developmental stages. These findings support the existence of a sensitive period during which 5-HT neurotransmission is likely to influence the formation of critical brain circuits that govern the expression of anxiety-related and repetitive behaviors. Future research is needed to unravel the complex set of neurobiological bases supporting aggressive features and other behavioral aberrances caused by MAO-A deficiency.

\section{Supplementary Material}

Refer to Web version on PubMed Central for supplementary material.

\section{Acknowledgments}

The present study was supported by National Institute of Health (NIH) grants (R01MH39085 to J.C.S., R21HD070611 to M.B.), Research Grant from the Tourette Syndrome Association (to MB), and the Boyd and Elsie Welin Professorship (to J.C.S.). This study was also partially supported by sub-awards (to M.B.) from the NIH grants P20 GM103638 and UL1 TR000001 (formerly UL1RR033179), awarded to the University of Kansas and University of Kansas Medical Center. The authors are indebted to the EU COST Action CM1103 "Structure-based drug design for diagnosis and treatment of neurological diseases: dissecting and modulating complex function in the monoaminergic systems of the brain" for supporting their international collaboration. The authors are grateful to Bogdan Olenyuk, Li Zhou, Jassmine Ren, Mona Dousti and Paradai Adisayathepkul for their valuable support in the execution of the experiments. No conflicts of interest were declared by any authors. None of the institutions had any further role in study design; in the collection, analysis and interpretation of data; in the writing of the report; and in the decision to submit the paper for publication.

\section{References}

Alia-Klein N, Goldstein RZ, Kriplani A, Logan J, Tomasi D, Williams B, et al. Brain monoamine oxidase A activity predicts trait aggression. J Neurosci. 2008; 28:5099-5104. [PubMed: 18463263]

Amen DG, Stubblefield M, Carmichael B. Brain SPECT findings and aggressiveness. Ann Clin Psychiatry. 1996; 8:129-137. [PubMed: 8899131]

Anderson GM, Horne WC, Chatterjee D, Cohen DJ. The hyperserotonemia of autism. Ann N Y Acad Sci. 1990; 600:331-340. discussion 341-332. [PubMed: 2252319]

Anderson GM, Freedman DX, Cohen DJ, Volkmar FR, Hoder EL, McPhedran P, et al. Whole blood serotonin in autistic and normal subjects. J Child Psychol Psychiatry. 1987; 28:885-900. [PubMed: 3436995]

Baldwin D, Rudge S. The role of serotonin in depression and anxiety. Int Clin Psychopharmacol. 1995; 9(Suppl 4):41-45. [PubMed: 7622823]

Bedard AC, Schulz KP, Cook EH Jr. Fan J, Clerkin SM, Ivanov I, et al. Dopamine transporter gene variation modulates activation of striatum in youth with ADHD. NeuroImage. 2010; 53:935-942. [PubMed: 20026227]

Bortolato M, Chen K, Shih JC. Monoamine oxidase inactivation: from pathophysiology to therapeutics. Adv Drug Deliv Rev. 2008; 60:1527-1533. [PubMed: 18652859]

Bortolato, M.; Chen, K.; Shih, JC. The degradation of serotonin: role of MAO. In: Muller, CL.; Jacobs, B., editors. Handbook of the Neurobiology of Serotonin. Elsevier; Burlington: 2010. p. 687-714.

Bortolato M, Chen K, Godar SC, Chen G, Wu W, Rebrin I, et al. Social deficits and perseverative behaviors, but not overt aggression, in MAO-A hypomorphic mice. Neuropsychopharmacology. 2011; 36:2674-2688. [PubMed: 21832987]

Bortolato M, Godar SC, Alzghoul L, Zhang J, Darling RD, Simpson KL, et al. e-pub ahead of print Jul 31:1-20. Monoamine oxidase A and A/B knockout mice display autistic-like features. Int J Neuropsychopharmacol. 2012a 
Bortolato M, Godar SC, Davarian S, Chen K, Shih JC. Behavioral disinhibition and reduced anxietylike behaviors in monoamine oxidase B-deficient mice. Neuropsychopharmacology. 2009; 34:2746-2757. [PubMed: 19710633]

Bortolato M, Godar SC, Melis M, Soggiu A, Roncada P, Casu A, et al. NMDARs mediate the role of monoamine oxidase A in pathological aggression. J Neurosci. 2012b; 32:8574-8582. [PubMed: 22723698]

Bortolato M, Pivac N, Muck Seler D, Nikolac Perkovic M, Pessia M, Di Giovanni G. The serotonergic system at the interface of aggression and suicide. Neuroscience. 2013 in press.

Boylan CB, Bennett-Clarke CA, Crissman RS, Mooney RD, Rhoades RW. Clorgyline treatment elevates cortical serotonin and temporarily disrupts the vibrissae-related pattern in rat somatosensory cortex. J Comp Neurol. 2000; 427:139-149. [PubMed: 11042596]

Brunner HG, Nelen M, Breakefield XO, Ropers HH, van Oost BA. Abnormal behavior associated with a point mutation in the structural gene for monoamine oxidase A. Science. 1993a; 262:578-580. [PubMed: 8211186]

Brunner HG, Nelen MR, van Zandvoort P, Abeling NG, van Gennip AH, Wolters EC, et al. X-linked borderline mental retardation with prominent behavioral disturbance: phenotype, genetic localization, and evidence for disturbed monoamine metabolism. Am J Hum Genet. 1993b; 52:1032-1039. [PubMed: 8503438]

Bruno RM, Khatri V, Land PW, Simons DJ. Thalamocortical angular tuning domains within individual barrels of rat somatosensory cortex. J Neurosci. 2003; 23:9565-9574. [PubMed: 14573536]

Casanova MF, Buxhoeveden DP, Switala AE, Roy E. Minicolumnar pathology in autism. Neurology. 2002; 58:428-432. [PubMed: 11839843]

Casanova MF, van Kooten IA, Switala AE, van Engeland H, Heinsen H, Steinbusch HW, et al. Minicolumnar abnormalities in autism. Acta neuropathologica. 2006; 112:287-303. [PubMed: $16819561]$

Cases O, Seif I, Grimsby J, Gaspar P, Chen K, Pournin S, et al. Aggressive behavior and altered amounts of brain serotonin and norepinephrine in mice lacking MAOA. Science. 1995; 268:17631766. [PubMed: 7792602]

Cases O, Vitalis T, Seif I, De Maeyer E, Sotelo C, Gaspar P. Lack of barrels in the somatosensory cortex of monoamine oxidase A-deficient mice: role of a serotonin excess during the critical period. Neuron. 1996; 16:297-307. [PubMed: 8789945]

Caspi A, McClay J, Moffitt TE, Mill J, Martin J, Craig IW, et al. Role of genotype in the cycle of violence in maltreated children. Science. 2002; 297:851-854. [PubMed: 12161658]

Chen K, Cases O, Rebrin I, Wu W, Gallaher TK, Seif I, et al. Forebrain-specific expression of monoamine oxidase A reduces neurotransmitter levels, restores the brain structure, and rescues aggressive behavior in monoamine oxidase A-deficient mice. J Biol Chem. 2007; 282:115-123. [PubMed: 17090537]

Chen L, Hamaguchi K, Ogawa M, Hamada S, Okado N. PCPA reduces both monoaminergic afferens and non-monoaminergic synapses in the cerebral cortex. Neurosci Res. 1994; 19:111-115. [PubMed: 8008232]

Coccaro EF. Central serotonin and impulsive aggression. Br J Psychiatry Suppl. 1989:52-62. [PubMed: 2692640]

Cohen IL, Liu X, Schutz C, White BN, Jenkins EC, Brown WT, et al. Association of autism severity with a monoamine oxidase A functional polymorphism. Clin Genet. 2003; 64:190-197. [PubMed: 12919132]

Cohen IL, Liu X, Lewis ME, Chudley A, Forster-Gibson C, Gonzalez M, et al. Autism severity is associated with child and maternal MAOA genotypes. Clin Genet. 2011; 79:355-362. [PubMed: 20573161]

Cui Y, Jin J, Zhang X, Xu H, Yang L, Du D, et al. Forebrain NR2B overexpression facilitating the prefrontal cortex long-term potentiation and enhancing working memory function in mice. PLoS One. 2011; 6:e20312. [PubMed: 21655294]

Daubert EA, Condron BG. Serotonin: a regulator of neuronal morphology and circuitry. Trends Neurosci. 2010; 33:424-434. [PubMed: 20561690] 
Davis LK, Hazlett HC, Librant AL, Nopoulos P, Sheffield VC, Piven J, et al. Cortical enlargement in autism is associated with a functional VNTR in the monoamine oxidase A gene. Am J Med Genet B Neuropsychiatr Genet. 2008; 147B:1145-1151. [PubMed: 18361446]

Fergusson DM, Boden JM, Horwood LJ, Miller AL, Kennedy MA. MAOA, abuse exposure and antisocial behaviour: 30-year longitudinal study. Br J Psychiatry. 2011; 198:457-463. [PubMed: 21628708]

Fink CC, Meyer T. Molecular mechanisms of CaMKII activation in neuronal plasticity. Curr Opin Neurobiol. 2002; 12:293-299. [PubMed: 12049936]

Godar SC, Bortolato M, Frau R, Dousti M, Chen K, Shih JC. Maladaptive defensive behaviours in monoamine oxidase A-deficient mice. Int J Neuropsychopharmacol. 2011; 14:1195-1207. [PubMed: 21156093]

Gogos JA, Morgan M, Luine V, Santha M, Ogawa S, Pfaff D, et al. Catechol-O-methyltransferasedeficient mice exhibit sexually dimorphic changes in catecholamine levels and behavior. Proc Natl Acad Sci U S A. 1998; 95:9991-9996. [PubMed: 9707588]

Guo G, Roettger ME, Shih JC. Contributions of the DAT1 and DRD2 genes to serious and violent delinquency among adolescents and young adults. Hum Genet. 2007; 121:125-136. [PubMed: 17120049]

Haller J, Bakos N, Rodriguiz RM, Caron MG, Wetsel WC, Liposits Z. Behavioral responses to social stress in noradrenaline transporter knockout mice: effects on social behavior and depression. Brain Res Bull. 2002; 58:279-284. [PubMed: 12128153]

Heim C, Nemeroff CB. The role of childhood trauma in the neurobiology of mood and anxiety disorders: preclinical and clinical studies. Biol Psychiatry. 2001; 49:1023-1039. [PubMed: 11430844]

Kim-Cohen J, Caspi A, Taylor A, Williams B, Newcombe R, Craig IW, et al. MAOA, maltreatment, and gene-environment interaction predicting children's mental health: new evidence and a metaanalysis. Mol Psychiatry. 2006; 11:903-913. [PubMed: 16801953]

Kolevzon A, Newcorn JH, Kryzak L, Chaplin W, Watner D, Hollander E, et al. Relationship between whole blood serotonin and repetitive behaviors in autism. Psychiatry Res. 2010; 175:274-276. [PubMed: 20044143]

Lauder JM, Krebs H. Serotonin as a differentiation signal in early neurogenesis. Dev Neurosci. 1978; 1:15-30. [PubMed: 158519]

Lucki I. The spectrum of behaviors influenced by serotonin. Biol Psychiatry. 1998; 44:151-162. [PubMed: 9693387]

Mejia JM, Ervin FR, Baker GB, Palmour RM. Monoamine oxidase inhibition during brain development induces pathological aggressive behavior in mice. Biol Psychiatry. 2002; 52:811821. [PubMed: 12372653]

Miczek KA, Maxson SC, Fish EW, Faccidomo S. Aggressive behavioral phenotypes in mice. Behav Brain Res. 2001; 125:167-181. [PubMed: 11682108]

Mulder EJ, Anderson GM, Kema IP, de Bildt A, van Lang ND, den Boer JA, et al. Platelet serotonin levels in pervasive developmental disorders and mental retardation: diagnostic group differences, within-group distribution, and behavioral correlates. J Am Acad Child Adolesc Psychiatry. 2004; 43:491-499. [PubMed: 15187810]

Olivier B. Serotonin and aggression. Ann N Y Acad Sci. 2004; 1036:382-392. [PubMed: 15817750]

Pellow S, Chopin P, File SE, Briley M. Validation of open:closed arm entries in an elevated plus-maze as a measure of anxiety in the rat. J Neurosci Methods. 1985; 14:149-167. [PubMed: 2864480]

Ritvo ER, Yuwiler A, Geller E, Ornitz EM, Saeger K, Plotkin S. Increased blood serotonin and platelets in early infantile autism. Arch Gen Psychiatry. 1970; 23:566-572. [PubMed: 5482649]

Rodriguiz RM, Chu R, Caron MG, Wetsel WC. Aberrant responses in social interaction of dopamine transporter knockout mice. Behav Brain Res. 2004; 148:185-198. [PubMed: 14684259]

Sacco R, Curatolo P, Manzi B, Militerni R, Bravaccio C, Frolli A, et al. Principal pathogenetic components and biological endophenotypes in autism spectrum disorders. Autism Res. 2010; 3:237-252. [PubMed: 20878720] 
Salichon N, Gaspar P, Upton AL, Picaud S, Hanoun N, Hamon M, et al. Excessive activation of serotonin (5-HT) 1B receptors disrupts the formation of sensory maps in monoamine oxidase a and 5-ht transporter knock-out mice. J Neurosci. 2001; 21:884-896. [PubMed: 11157075]

Saudou F, Amara DA, Dierich A, LeMeur M, Ramboz S, Segu L, et al. Enhanced aggressive behavior in mice lacking 5-HT1B receptor. Science. 1994; 265:1875-1878. [PubMed: 8091214]

Schain RJ, Freedman DX. Studies on 5-hydroxyindole metabolism in autistic and other mentally retarded children. J Pediatr. 1961; 58:315-320. [PubMed: 13747230]

Scott AL, Bortolato M, Chen K, Shih JC. Novel monoamine oxidase A knock out mice with humanlike spontaneous mutation. Neuroreport. 2008; 19:739-743. [PubMed: 18418249]

Shih JC, Chen K, Ridd MJ. Monoamine oxidase: from genes to behavior. Ann Rev Neurosci. 1999; 22:197-217. [PubMed: 10202537]

Spijker, S. Dissection of rodent brain regions. In: Ka Wan, Li, editor. Neuroproteomics, Neuromethods. Vol. 57. Springer Science; 2011. p. 13-26.

Strack S, McNeill RB, Colbran RJ. Mechanism and regulation of calcium/calmodulin-dependent protein kinase II targeting to the NR2B subunit of the N-methyl-D-aspartate receptor. J Biol Chem. 2000; 275:23798-806. [PubMed: 10764765]

Summers CH, Korzan WJ, Lukkes JL, Watt MJ, Forster GL, Overli O, et al. Does serotonin influence aggression? comparing regional activity before and during social interaction. Physiol Biochem Zool. 2005; 78:679-694. [PubMed: 16059845]

Takahashi A, Quadros IM, de Almeida RMM, Miczek KA. Brain serotonin receptors and transporters: initiation vs. termination of escalated aggression. Psychopharmacology. 2011; 213:183-212. [PubMed: 20938650]

Virkkunen M, Linnoila M. Brain serotonin, type II alcoholism and impulsive violence. J Stud Alcohol Suppl. 1993; 11:163-169. [PubMed: 8410958]

Vitalis T, Cases O, Callebert J, Launay JM, Price DJ, Seif I, et al. Effects of monoamine oxidase A inhibition on barrel formation in the mouse somatosensory cortex: determination of a sensitive developmental period. J Comp Neurol. 1998; 393:169-184. [PubMed: 9548695]

Vitalis T, Cases O, Passemard S, Callebert J, Parnavelas JG. Embryonic depletion of serotonin affects cortical development. Eur J Neurosci. 2007; 26:331-44. [PubMed: 17650110]

Volavka J, Bilder R, Nolan K. Catecholamines and aggression: the role of COMT and MAO polymorphisms. Ann N Y Acad Sci. 2004; 1036:393-398. [PubMed: 15817751]

Wang M, Yang Y, Wang CJ, Gamo NJ, Jin LE, Mazer JA, et al. NMDA receptors subserve persistent neuronal firing during working memory in dorsolateral prefrontal cortex. Neuron. 2013; 77:73649. [PubMed: 23439125]

Whitaker-Azmitia PM, Zhang X, Clarke C. Effects of gestational exposure to monoamine oxidase inhibitors in rats: preliminary behavioral and neurochemical studies. Neuropsychopharmacology. 1994; 11:125-132. [PubMed: 7840864]

Xu Y, Sari Y, Zhou FC. Selective serotonin reuptake inhibitor disrupts organization of thalamocortical somatosensory barrels during development. Brain Res Dev Brain Res. 2004; 150:151-161.

Yirmiya N, Pilowsky T, Tidhar S, Nemanov L, Altmark L, Ebstein RP. Family-based and population study of a functional promoter-region monoamine oxidase A polymorphism in autism: possible association with IQ. Am J Med Genet. 2002; 114:284-287. [PubMed: 11920849] 


\section{HIGHLIGHTS}

$>\quad$ Monoamine oxidase (MAO) A catalyzes the degradation of serotonin (5-HT).

$>\quad$ MAO A knockout (KO) mice display high 5-HT levels, aggression and perseverative behaviors.

$>\quad$ MAO A KO pups were treated with the 5-HT synthesis inhibitor $p$-chlorophenylalanine (pCPA).

$>\quad$ Early pCPA treatment reduced perseveration, but not aggression in MAO A $\mathrm{KO}$ mice 


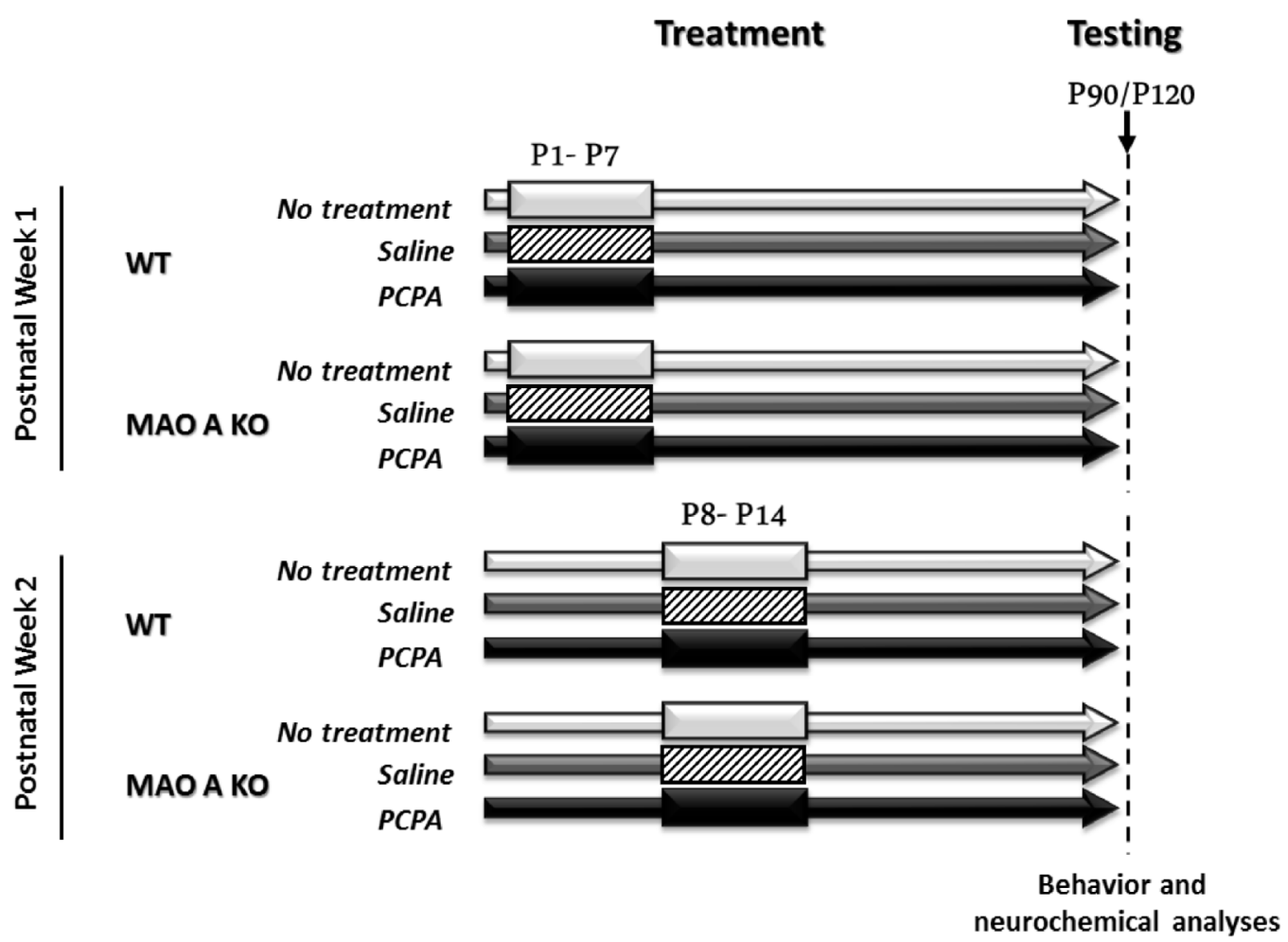

Figure 1.

Schematic representation of the experimental design for pCPA administration during the first two postnatal weeks. Behavioral analyses were performed between postnatal day 90 and postnatal day 120 (corresponding to adulthood). 
A

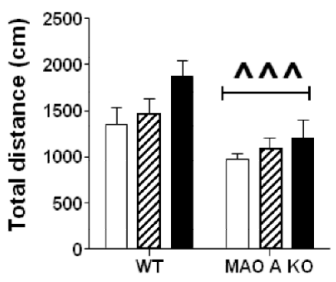

B

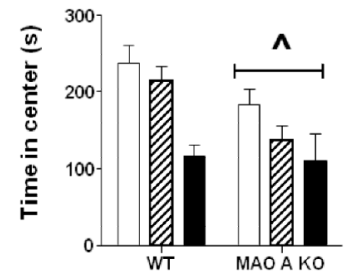

C

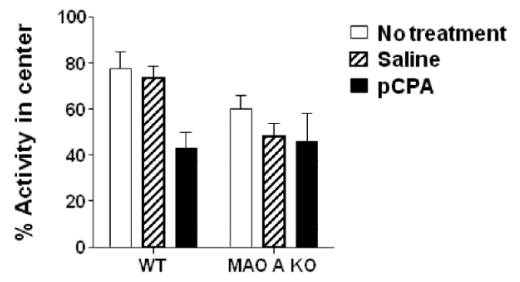

Figure 2.

Effects of pCPA treatment from postnatal day 1 through 7 on open-field behaviors in adult wild type (WT) and MAO-A KO mice. Values are represented as mean $\pm \mathrm{SEM} .{ }^{\wedge} \mathrm{P}<0.05$; $\wedge \wedge \wedge \mathrm{P}<0.001$ compared to WT mice (main effect of genotype). Main effects of treatment are not indicated. For more details, see text. 
A
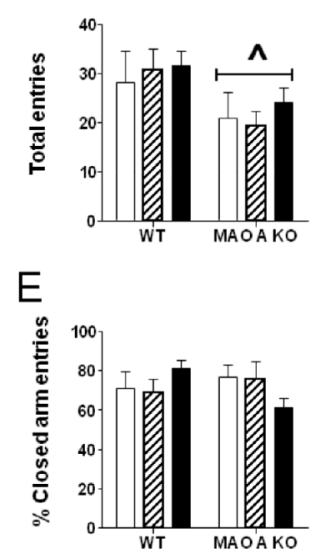

B
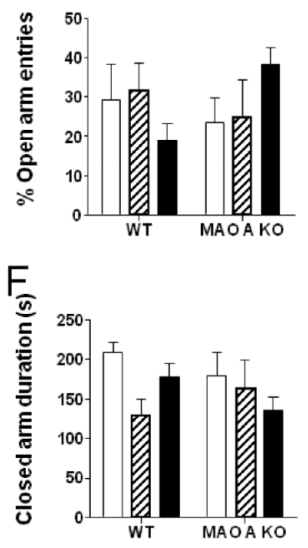
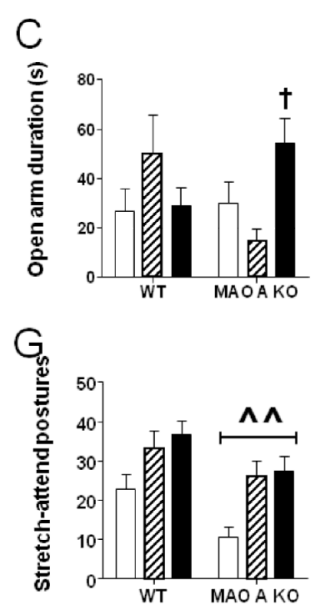

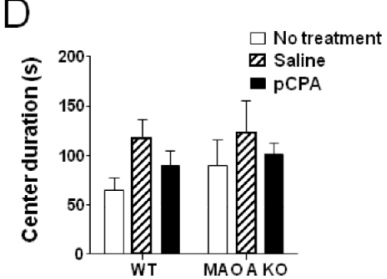

$\mathrm{H}$
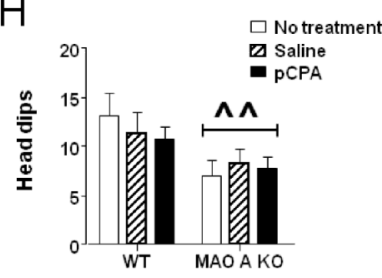

Figure 3.

Effects of pCPA treatment from postnatal day 1 through 7 on elevated-plus maze behaviors in adult wild type (WT) and MAO-A KO mice. Values are represented as mean $\pm \mathrm{SEM}$. $\wedge \mathrm{P}<0.05 ;{ }^{\wedge} \wedge \mathrm{P}<0.001$ compared to WT mice (main effect of genotype). ${ }^{\dagger} \mathrm{P}<0.05$ compared to MAO-A KO mice treated with saline. For more details, see text. 
A

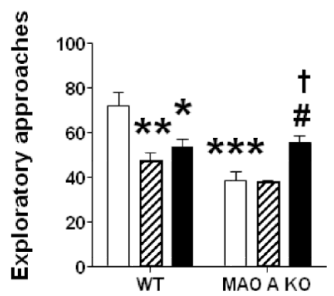

B

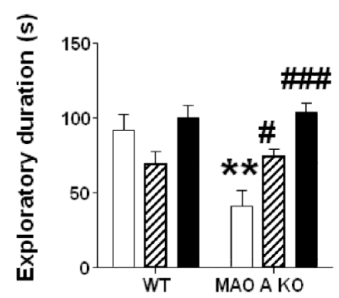

C

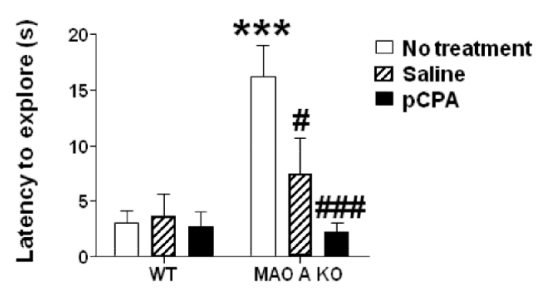

Figure 4.

Effects of pCPA treatment from postnatal day 1 through 7 on the proclivity of adult wild type (WT) and MAO-A KO mice to explore a novel object in their home cage. Values are represented as mean \pm SEM. $* \mathrm{P}<0.05 ; * * \mathrm{P}<0.01 ; * * * \mathrm{P}<0.001$, compared to untreated WT mice. ${ }^{\#} \mathrm{P}<0.05 ;{ }^{\# \# \#} \mathrm{P}<0.001$, compared to untreated MAO-A-deficient mice; ${ }^{\dagger} \mathrm{P}<0.05$, compared to saline-treated MAO-A KO mice. For more details, see text. 
A

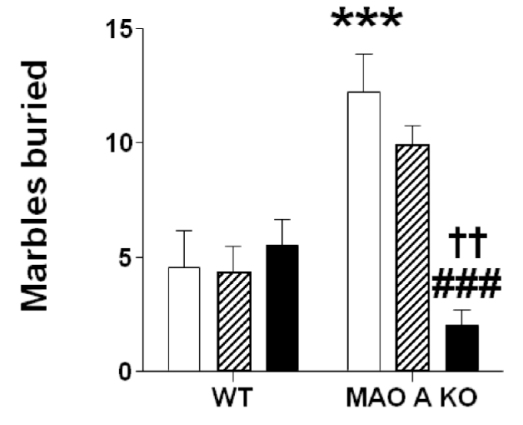

B

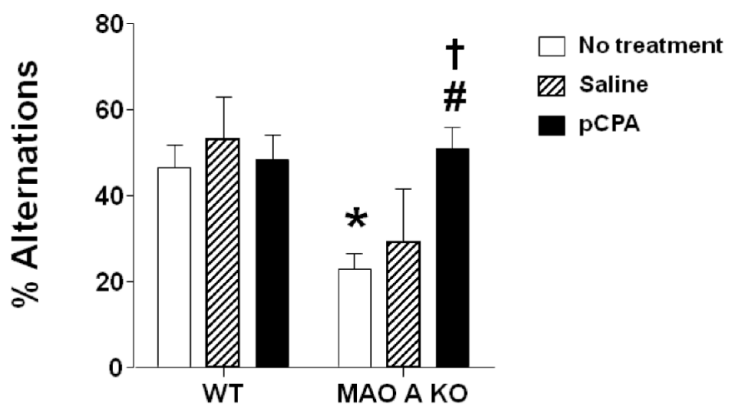

Figure 5.

Effects of pCPA treatment from postnatal day 1 through 7 on A) marble-burying behavior and B) spontaneous alternations in a T-maze of adult wild type (WT) and MAO-A KO mice. Values are represented as mean \pm SEM. $* \mathrm{P}<0.05 ; * * * \mathrm{P}<0.001$, compared to untreated WT mice. ${ }^{\#} \mathrm{P}<0.05 ;{ }^{\# \# \#} \mathrm{P}<0.001$, compared to untreated MAO-A-deficient mice; ${ }^{\dagger} \mathrm{P}<0.05 ;{ }^{\dagger} \mathrm{P}<0.01$ compared to saline-treated MAO-A KO mice. For more details, see text. 
A

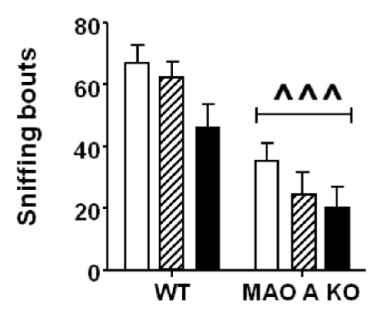

C

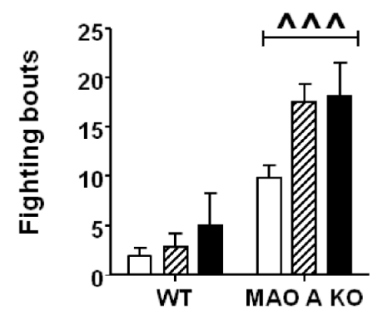

B

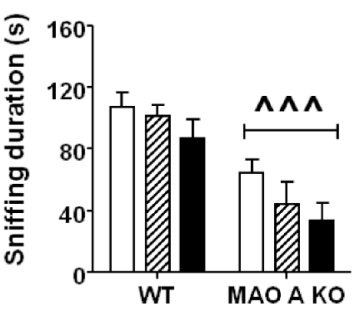

D

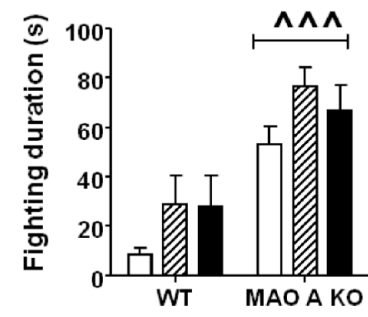

$\square$ No treatment

$\square$ Saline

pCPA

Figure 6.

Effects of pCPA treatment from postnatal day 1 through 7 on A-B) social interaction and CD) resident-intruder aggression in adult wild type (WT) and MAO-A KO mice. Values are represented as mean \pm SEM. ${ }^{\wedge} \wedge \mathrm{P}<0.001$ compared to WT mice (main effect of genotype). For more details, see text. 
A

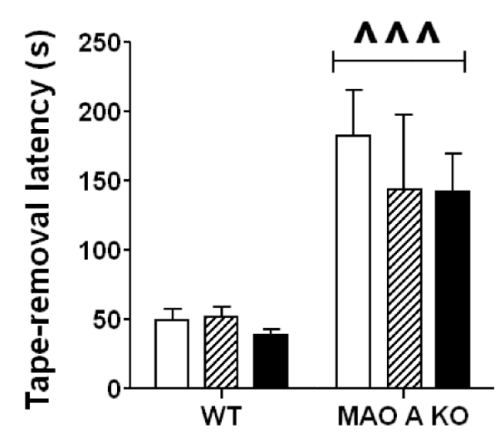

$\mathrm{B}$

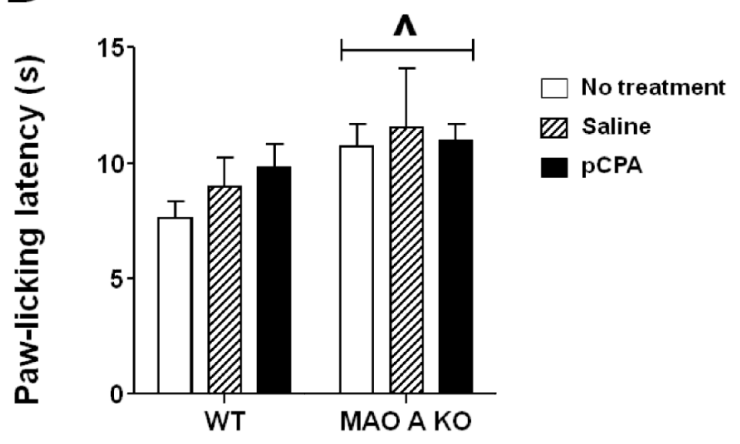

Figure 7.

Effects of pCPA treatment from postnatal day 1 through 7 on the latencies to A) remove a sticky tape from the paws and B) lick paws in the hot plate test of adult wild type (WT) and MAO-A KO mice. Values are represented as mean \pm SEM. $\wedge^{\wedge}<0.05 ; \wedge \wedge \wedge \mathrm{P}<0.001$ compared to WT mice (main effect of genotype). For more details, see text. 
A

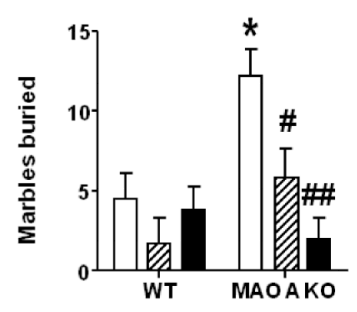

D

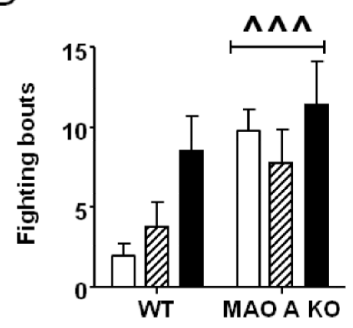

B

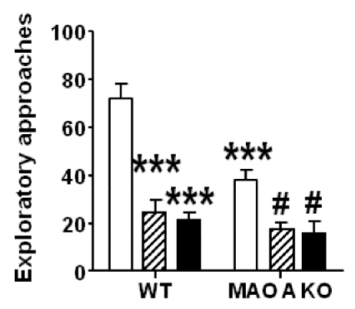

$E$

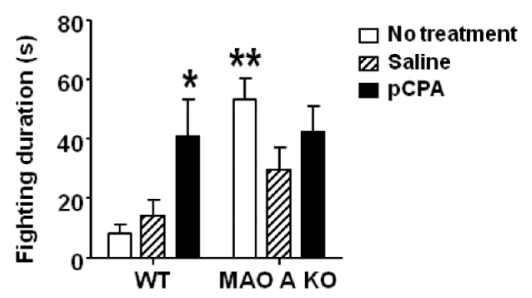

Figure 8.

Effects of pCPA treatment from postnatal day 8 through 14 on A) marble-burying behavior, B-C) novel-object exploration; and D-E) resident-intruder responses of adult wild type (WT) and MAO-A KO mice. Values are represented as mean $\pm \mathrm{SEM}$. ${ }^{\wedge} \mathrm{P}<0.05 ; \wedge \wedge \wedge \mathrm{P}<0.001$ compared to WT mice (main effect of genotype); $* \mathrm{P}<0.05$; $* * * \mathrm{P}<0.001$, compared to untreated WT mice. ${ }^{\#} \mathrm{P}<0.05 ;{ }^{\#} \mathrm{P}<0.01$, compared to untreated MAO-A-deficient mice. Main effects of treatment are not indicated. For more details, see text. 


\section{Table 1}

Effects of postnatal pCPA treatment from postnatal day 1 through 8 on 5-HT forebrain concentrations in 8-day old (P8) and adult (90-day old; P90) mice. Values are displayed as mean \pm SEM.

\begin{tabular}{|c|l|l|l|}
\hline \multicolumn{2}{|c|}{ Table 1 } & \multicolumn{1}{|c|}{$\begin{array}{c}\text { P8 - FOREBRAIN } \\
\text { (pg/mg of tissue) }\end{array}$} & $\begin{array}{c}\text { P90 - PREFRONTAL CORTEX } \\
\text { (pg/mg of tissue) }\end{array}$ \\
\hline \multirow{3}{*}{ WT } & Untreated & $300.02 \pm 27.48$ & $393.44 \pm 45.05$ \\
& Saline & $384.92 \pm 38.80$ & $316.21 \pm 40.08$ \\
& pCPA & $163.32 \pm 29.04^{*} \diamond$ & $125.11 \pm 15.74^{* * * \diamond}$ \\
\hline \multirow{4}{*}{ MAO A KO } & Untreated & $944.45 \pm 58.51^{* * *}$ & $590.68 \pm 54.17^{* *}$ \\
& Saline & $1012.87 \pm 35.36^{*} \diamond \diamond$ & $594.61 \pm 52.03^{\# \# \#}$ \\
& pCPA & $266.88 \pm 21.17^{\# \# \dagger \dagger}$ & $101.59 \pm 17.23^{\# \# \dagger \dagger}$ \\
\hline
\end{tabular}

Main effects are not indicated. For further details, see text.

* $\mathrm{P}<0.05$;

*** $\mathrm{P}<0.01$

*** $\mathrm{P}<0$

$\mathrm{P}<0.001$, compared to untreated WT mice.

$\diamond_{\mathrm{P}<0.05}$

$\diamond_{\mathrm{P}<0.01 ;}$

$\infty_{\mathrm{P}<0.001, \text { compared to saline-treated WT mice. }}$

${ }^{\# \# \# ~} \mathrm{P}<0.001$ compared to untreated MAO A KO mice.

${ }^{\dagger \dagger} \mathrm{P}<0.001$ compared to saline-treated MAOA KO mice. 


\section{Table 2}

Effects of postnatal pCPA treatment from postnatal day 1 through 7 on NMDA receptor subunit expression in the prefrontal cortex of adult WT and MAO-A KO mice.

\begin{tabular}{|c|c|c|c|c|}
\hline \multicolumn{2}{|c|}{ Table 2 } & NR1 & NR2A & NR2B \\
\hline \multirow{2}{*}{ WT } & Saline & $1.062 \pm 0.116$ & $1.066 \pm 0.154$ & $1.018 \pm 0.243$ \\
& pCPA & $1.052 \pm 0.136$ & $0.980 \pm 0.178$ & $1.116 \pm 0.168$ \\
\hline \multirow{3}{*}{ MAO A KO } & Saline & $0.992 \pm 0.129$ & $1.083 \pm 0.203$ & $1.538 \pm 0.222^{\wedge \wedge \wedge}$ \\
& pCPA & $1.062 \pm 0.105$ & $0.958 \pm 0.113$ & $1.578 \pm 0.249^{\wedge \wedge \wedge}$ \\
\hline
\end{tabular}

Values represented as mean \pm SEM.

$\wedge \wedge$

$\mathrm{P}<0.001$, compared to WT mice (main effect of genotype). For further details, see text. 